\title{
Retinol and Adrenal Lipids of Rats
}

\author{
U. K. MisRA \\ Department of Radioisotopes and Biochemistry \\ V.P. Chest Institute, Universitty of Delhi \\ Delhi-7, India
}

(Received February 14, 1969)

\begin{abstract}
Effect of oral feeding of $14,400,28,800,57,600$ and 93,600 I.U. of retinol respectively daily for 10 days on the adrenal lipids of adult rats has been studied. Feeding of different amounts of retinol enlarged the adrenal glands, and brought about marked elevations in adrenal total lipids, esterified and free cholesterol, triglycerides and all the phospholipids.
\end{abstract}

Studies on the cholesterol metabolism in hypo- and hypervitaminotic A rats, have implicated the role of vitamin $\mathrm{A}$ in isoprene metabolism particularly at the squalene step (1-3). Gloor and Wiss reported that in vitamin A deficient rats the incorporation of mevalonate- $2 \cdot{ }^{14} \mathrm{C}$ into liver ubiquinone and squalene was increased, whereas in sterol fraction it was decreased (2). Rao and Olson have recently demonstrated that administration of large amounts of vitamin $\mathrm{A}$ to adult rats increased the incorporation of mevalonate- $2 \cdot{ }^{14} \mathrm{C}$ into liver cholesterol and decreased in ubiquinone and squalene (3). As adrenals contain very high amounts of cholesterol on unit weight basis, and since the role of vitamin $\mathrm{A}$ has been implicated in isoprene metabolism, this investigation was undertaken to examine the effects of feeding different amounts of retinol on neutral lipids and phospholipids of adrenals of adult rats. The results show that feeding of large amounts of retinol markedly raises adrenal lipids, cholesterol and phospholipids of adult rats.

\section{Methods ANd Meterials}

\section{Animals}

Thirty male rats (Wistar strain) weighing 150-180 g (9-10 months old) from our Institute's maintained colony were used. They were housed in individual cages and were fed a stock diet of the following composition: Casein 20 parts; hydrogenated fat 10 parts; potato starch 60 parts; dried yeast powder 5 parts; and salt mixture 5 parts (4). In addition, each rat received $4 \mathrm{~g}$ germinating grams (chickpea) daily. The rats had free access to water.

\section{Treatment}

The rats were divided in five groups of six each. Four groups (I-IV) were orally fed 14,400, 28,800, 57,600 and 93,600 I.U. of retinol (Prepalin, Glaxo Private 
Ltd., India, a vitamin A alcohol concentrate) respectively daily for ten days. The fifth group was the control and received saline orally for the same period. Daily records of their food consumption and tri-weekly records of the body weights were maintained. On the 10th day the rats in all the group were sacrificed by decapitation, and both adrenals and livers removed, cleaned, rinsed with ice cold saline, wiped, weighed and immersed in a volume of chloroform-methanol $(2: 1, \mathrm{v} / \mathrm{v})$ solvent mixture. The adrenals from three animals in each group were pooled, ground in a mortar and pestle and processed for lipid extraction as published earlier (5). The extraction of liver lipids for vitamin A assay was also done according to the method published earlier (5). Final lipid solutions of adrenal and liver were made in a known volume of chloroform and stored at $-8^{\circ}$ until used for analysis.

\section{Solvents}

All solvents used were freshly distilled before use.

\section{Analysis}

Total lipids were estimated by drying an aliquot and weighing it to a constant weight in a glass thimble. Total cholesterol was estimated by the method of Hanel and Dam (6). Phospholipid phosphorus was assayed by the method of Bartlett (7) as modified by Marinetti (8). Glycerides were determined by the assay of glyceride-glycerol (9) and by difference (total lipids-cholesterol-phospholipids). Vitamin A in liver lipid extracts was estimated by the method of Carr-Price (10).

\section{Quantitative Thin Layer Chromatography}

Adrenal neutral lipids and phospholipids were separated by means of thin layer chromatography on silica gel $\mathrm{G}$ coated plates. The conditions of thin layer chromatography, location, identification and estimation of respective neutral lipid and phospholipid fractions were essentially the same as published earlier (11). The recoveries of applied neutral lipids and phospholipids from the plates were between 92-95 and 96-100 per cent respectively.

\section{RESULTS}

The effect of feeding 14,400, 28,800, 57,600 and 93,600 I.U. of retinol daily for 10 days to adult rats on their body weights and daily food consumption as compared to the control is shown in Table 1. Rats fed varying amounts of retinol showed loss in daily food consumption and body weights usually 4-5 days after the feeding. These effects were much more pronounced in rats fed 93,600 I.U. of retinol than in those fed $14,400,28,800$ and 57,600 I.U. of retinol. The rats developed dosedependent retinol toxicity symptoms such as epilation, bent and limping posture, bleeding around the nose and eyes and internal haemorrhages on both right and left front and back limb joints and neck. Similar symptoms have been reported by Moore and Wang in orally fed rats (12).

The amounts of liver vitamin $\mathrm{A}(\mu \mathrm{g} / \mathrm{g}$ wet tissue) in group I, II, III and IV were $258.1 \pm 34.81,422.44 \pm 73.79,808.7 \pm 143.20$ and $668.5 \pm 66$ respectively as compared to the control group value of $76.28 \pm 21.260$.

Rats fed varying amounts of retinol for ten days showed marked enlargement 
TABLE 1

Effect of Feeding Retinol on Adrenal Lipids of Rats

\begin{tabular}{|c|c|c|c|c|c|}
\hline & \multicolumn{5}{|c|}{ I.U. of retinol fed daily for 10 days } \\
\hline & None & 14,400 & 28,800 & 67,600 & 93,600 \\
\hline \multicolumn{6}{|l|}{ Body weight $(g)$} \\
\hline Start & $166.0 \pm 8.53$ & $168.6 \pm 7.34$ & $167.0 \pm 8.04$ & $166.0 \pm 3.42$ & $170.8 \pm 9.91$ \\
\hline End & $172.0 \pm 9.99$ & $172.2 \pm 5.87$ & $167.0 \pm 7.75$ & $161.1 \pm 3.83$ & $145.0 \pm 4.15$ \\
\hline $\begin{array}{l}\text { Daily food } \\
\text { consumption } \\
(\mathrm{g} / \mathrm{rat} / \text { day })\end{array}$ & $14.2 \pm 0.690$ & $13.3 \pm 0.783$ & $10.6 \pm 0.783$ & $11.4 \pm 1.000$ & $6.7 \pm 0.677$ \\
\hline \multirow[t]{2}{*}{$\begin{array}{l}\text { Adrenal weight } \\
\qquad(m g)\end{array}$} & 16.66 & 26.6 & 26.6 & 28.7 & 30.0 \\
\hline & \multicolumn{5}{|c|}{$m g / g$ wet tissue } \\
\hline Lipids & 100.00 & 137.50 & 148.76 & 147.76 & 173.12 \\
\hline Cholesterol & 17.22 & 24.87 & 33.06 & 34.48 & 24.25 \\
\hline Phospholipids & 16.90 & 30.20 & 31.98 & 35.58 & 37.78 \\
\hline Glycerides & 65.90 & 84.43 & 83.49 & 77.77 & 111.08 \\
\hline
\end{tabular}

TABLE 2

Effect of Feeding Retinol on the Adrenal Neutral lipids of Rats

\begin{tabular}{|c|c|c|c|c|c|}
\hline & \multicolumn{5}{|c|}{ I.U. of retinol fed daily for 10 days } \\
\hline & None & 14,400 & 28,800 & 57,600 & 93,600 \\
\hline & \multicolumn{5}{|c|}{$m g / g$ wet weight } \\
\hline Free cholesterol & 0.774 & 3.767 & 2.243 & 2.426 & 3.838 \\
\hline Esterified cholesterol & 16.432 & 21.090 & 30.798 & 31.915 & 19.688 \\
\hline Monoglycerides & 17.685 & 5.874 & 9.135 & 5.208 & 11.041 \\
\hline Diglycerides & 13.264 & 5.294 & 10.879 & 7.491 & 7.628 \\
\hline Triglycer!des & 34.880 & 73.057 & 63.420 & 65.530 & 92.406 \\
\hline
\end{tabular}

TABLE 3

Effect of Feeding Retinol to Adult Rats on the Adrenal Phospholipids

\begin{tabular}{lrrrrr}
\hline & \multicolumn{5}{c}{ I.U. of retinol fed daily for 10 days } \\
\cline { 2 - 6 } & None & 14,400 & 28,800 & 67,600 & 93,600 \\
\hline & 47.48 & 151.96 & 159.09 & 115.00 & 164.49 \\
$\begin{array}{l}\text { Origin + phosphatidyl } \\
\text { inositol }\end{array}$ & 43.06 & 104.48 & 90.87 & 90.60 & 85.76 \\
$\begin{array}{l}\text { Phosphatidyl serine } \\
\text { Lysophatidyl choline }\end{array}$ & 48.02 & 87.00 & 74.21 & 89.29 & 141.68 \\
$\begin{array}{l}\text { Lysophosphatidyl ethanolamine+ } \\
\text { sphingomyelin }\end{array}$ & 52.98 & 95.48 & 122.21 & 108.40 & 130.79 \\
$\begin{array}{l}\text { Phosphatidyl choline } \\
\text { Phosphatidyl ethanolamine }\end{array}$ & 258.89 & 434.48 & 480.12 & 555.01 & 583.56 \\
$\begin{array}{l}\text { Phoshatidic acid }+ \\
\text { polyglycerol phosphatide }\end{array}$ & 144.07 & 178.00 & 203.90 & 307.23 & 227.15 \\
\hline
\end{tabular}


of adrenals (Table 1). Administration of retinol markedly increased adrenal total lipids, total cholesterol, total phospholipids and total glycerides as compared to untreated controls. The increases observed in adrenal total cholesterol of retinol treated rats were both in esterified and free cholesterol fraction (Table 2), but were more pronounced (3-4 fold) in free cholesterol fraction. In glycerides marked reductions were observed in adrenal mono- and diglycerides, whereas triglycerides showed pronounced increases in retinol treated rats as compared to control rats (Table 2). On expressing these results in terms of percentages of neutral lipids similar trend was noted.

Marked increases were noted in the concentration ( $\mu \mathrm{g}$ lipid phosphorus/g wet tissue) of all phospholipids in retinol treated rats as compared to control group rats (Table 3). On expressing the distribution of adrenal phospholipids in terms of percentages of total phospholipids, the percentage composition of all phospholipids in retinol treated rats was nearly comparable to that of control rats.

\section{Discussion}

The results obtained on the effects of feeding large amounts of retinol to adult rats, show that administration of vitamin A markedly influences the adrenal lipid metabolism, resulting in pronounced increases in all lipid components (Tables 1-3). The increases noted in both esterified and free cholesterol fractions (Tables 1 and 2) clearly point out that vitamin A does influence the adrenal cholesterol metabolism. Whether this is a direct or indirect effect of vitamin A is not certain at this stage, but similar results have been reported by Rao and Olson (3) and Misra (13) in liver of hypervitaminotic A rats.

The increase observed in adrenal glycerides was accompanied by a simultaneous decrease in both monoglycerides and diglycerides (Table 2). This increase in triglycerides perhaps results either from its increased synthesis or decreased utilization or both. The decrease noted in mono- and diglycerides (Table 2), point out towards an enhanced synthesis and accumulation of triglycerides in adrenals of rats fed retinol as compared to the control rats. An increase in total hepatic lipids, glycerides and fatty acids in livers of hypervitaminotic A rats have similarly been observed $(13,14)$. In view of Gillman and Gilbert $(16,17)$ suggestion on the role of endocrine gland metabolism in the production of nutritional fatty liver and deposition of glycogen in liver, it can be conceived that the stimulated metabolism of adrenals in excess retinol fed rats may have some role in fatty liver production and increased amounts of liver glycogen, observed in hypervitaminotic A rats (18).

The increases observed in the concentration of adrenal phospholipids (Tables 1 and 3) in retinol fed rats as compared to control group, may be an overall effect of increased synthesis of phospholipids either by CDP-diglyceride pathway or by interconversions. The results do suggest some role of retinol in phospholipid metabolism in adrenals. Whether this role is a direct one or an indirect one remains unsettled at this stage.

\section{ACKNOWLEDGMENT}

Technical assistance af Mr. N. Srivastava is acknowledged. 


\section{REFERENCES}

1. Heaton, F. W., Lowe, J.S., and Morton, R. A., Biochem. J., 67, 208 (1957).

2. Gloor, U., and Wiss, O., Biochim. Biophys. Res. Commun., 1, 182 (1959).

3. SubbaRao, K., and Olson, R. E., Biochim. Biophys. Acta, 136, 406 (1967).

4. Steenbock, H., and Nelson, E. M., J. Biol. Chem., 56, 355 (1923).

5. Misra, U. K., Indian J. Biochiem. 4, 125 (1967).

6. Hanel, H. K., and Dam, H., Acta Chem. Scand., 9, 677 (1955).

7. Bartlett, G. R., J. Biol. Chem., 234, 466 (1959).

8. Marinetti, G. V., J. Lipid Res., 3, 1 (1962).

9. Van Handel E., and Zilversmit, D. B., J. Lab. Clin. Invest., 50, 152 (1957).

10. Carr, P. H., and Price, E. A., Biochem. J., 20, 497 (1926).

11. Misra, U. K., Indian J. Biochem., 4, 136 (1967).

12. Moore, T., and Wang, Y. L., Biochem. J., 39, 222 (1945).

13. Misra, U. K., Canad. J. Biochem., 46, 697 (1968).

14. Misra, U. K., Canad. J. Biochem., 43, 1885 (1965).

15. Stein, Y., and Shapiro, B., Biochim. Biophys. Acta, 24, 197 (1957).

16. Gillman, J., and Gilbert, C., Brit. Med. J., 1, 57 (1958).

17. Gillman J., and Gilbert, C., Metabolism, 11, 800 (1962).

18. Kumar, M., Misra U.K., and Venkitasubramnian, T.A., Naturezvissenschaften, 52, 39 (1965). 